\title{
High Poloidal Beta Equilibria in TFTR Limited by a Natural inboard Poloidal Field Null*
}

PPEL --2775

S. A. Sahbagh, $\uparrow$ R. A. Gross, M. E. Mauel, and G. A. Navratil

DE91 016214 Deparment of Applied Physics, Columbia University, New York. New York 10027

M. G. Bell, R. Bell, M. Bitter, N. L. Bretz, R. V. Budny, C.E. Bush, M.S. Chance, P. C. Efthimion, E. D. Fredrickson, A. Hatcher, R. J. Hawryluk, S.P. Hirshman, ${ }^{\dagger \dagger}$ A. C. Janos, S.C. Jardin, D. L. Jassby, J. Manickam, D. C. McCune, K. M. McGuire, S. S. Medley, D. Muelier, Y. Nagayana, D. K. Owens, M. Okabayashi, H. K. Park, A. T. Ramsey, B. C. Stratton, E. J. Synakowski, G. Taylor, R. M. Wieland, and M.C. Zarnstorff

P!asmo Physics Laboratory. Princeton Universicy, Princeton. New jersey 08543

J. Kesner, E. S. Marmar, and J. L.Terny

AIT Plasma 5usion Censer, Massachusens Instinule of Technology. Cambridge, Massachusetrs 02139

Recent operation of the Tokamak Fusion Test Reactor, TFTR, [Plasma Phys, and Contr. Nucl. Fus. Rearch, 1, 51 (1986)] has produced plasma equilibria with values of $\Lambda \equiv \beta_{p e q}+l_{i} / 2$ as large as 7, $E \beta_{p}$ dia $\equiv 2 \mu_{0} \varepsilon<p_{\perp}>/<<B_{p}>>^{2}$ as large as 1.6, and Troyon normalized diamagnetic beta [Plasma Phys. Contr. Fusion 26, 209 (1984); Phys. Lett. $110 \mathrm{~A}, 29$ (1985)], $\beta_{N \text { dia }} \equiv 10^{8}<\beta_{i \perp}>a B_{0} / I_{p}$ as large as 4.7 . When $\varepsilon \beta_{p \text { dia }} \geq 1.25$, a separatrix entered the vacuum chamber, producing a naturally diverted discharge which was sustained for many energy confinement times, $\tau_{E}$. The largest values of $\varepsilon \beta_{p}$ and plasma stored energy were obtained when the plasma current was ramped down prior to neutral beam injection. The measured peak ion and 
electron temperatures were as large as $24 \mathrm{keV}$ and $8.5 \mathrm{keV}$, respectively. Plasma stored energy in excess of $2.5 \mathrm{MJ}$ and $\tau_{E}$ greater than $130 \mathrm{msec}$ were obtained. Confinement times of greater than 3 times that expected from L-mode predictions have been achieved. The fusion power gain, $Q_{D D}$, reached a value of $1.3 \times 10^{-3}$ in a discharge with $I_{p}=1 \mathrm{MA}$ and $\varepsilon \beta_{p}$ dia $=0.85$. A large, sustained negative loop voltage during the steady state portion of the discharge :indicates that a substantia! non-inductive component of $I_{p}$ exists in these plasmas. Transport code analysis indicates that the bootstrap current constitutes up to $65 \%$ of $I_{p}$. Magnetohydrodynamic (MFID) ballooning stability analysis shows that while these plasmas are near, or at the $\beta_{p}$ limit, the pressure gradient in the plasma core is in the first region of stability to high $-n$ modes.

\footnotetext{
*Paper 4I6. Bull. Am. Phys. Soc. 35, 1992 (1990).

tPiesent address: Princeton Plasma Physics Laboratory, Princeton Universiry, Princeton, N.J. 08543

ItPresent address: Oak Ridge National Laboralory. Oak Ridge. Tennessee 37830
} 


\section{i. INTRODUCTION}

A significant concern regarding the next generation of tokamak fusion experiments and fusion reacior concepts is the large toroidal plasma current, $I_{p}$, needed to provide sufficient energy confinement to sustain fusion burn conditions in these devices. If improved confinement and adequate stability can be achieved, operation at high poloidal beta, $\beta_{p}$, can alleviate many problems associated with conventional tokamak reactor designs ${ }^{1.2}$. Operation at lower $I_{p}$ associated with high $\beta_{p}$ considerably reduces the adverse consequences of plasma disruptions. The power requirements for steady state current drive are reduced at lower $I_{g}$. In addition, a significant amount of neoclassical bootstrap current ${ }^{3-5}$ is predicted to form at high $\beta_{p}$ which could further reduce current drive requirements.

Capitalizing on these advantages, several reactor design studies including the ARIES6 and the JAERI Steady State Tokamak Reactor, SSTR ${ }^{7}$ designs, have incorporated fusion plasma operation at high $\beta_{p}$. However, since experience from the operation of large cokamaks has generally been at relatively small values of $\beta_{p}$ (less than the tokamak aspect rano), high $\beta_{p}$ reactor designs have been considered speculative, regardless of the benefits they may present. The demonstration of stable, high $\beta_{p}$ plasma operation in present large tokamak devices would begin to provide the experimental basis for the design of such a bigh $\beta_{p}$ reactor.

This paper presents results from recent experiments in the Tokamak Fusion Test Reactor, TFTR, 8 which have produced plasmas with very large values of $\beta_{p}$. While high $\beta_{p}$ plasmas have been achieved in other tokamaks, ${ }^{9-12}$ these are the first experiments that demonstrate stable plasma equilibria, limited by a natural inboard poloidal field null at high $\beta_{p}$, that are sustained for many energy confinement times, $\tau_{E}$, in a large neutral beam heated device. The methods employed to prodice these plasmas and the plasma parameters achier ad are described in the next section. A preliminary analysis of stability, confinement, non-inductive current drive, and neutron production for these high $\beta_{p}$ plasmas is presented in the subsequent sections. 


\section{Plasma parameters and operation at high $\beta_{F}$}

Stable plasmas with $\beta_{p \text { dia }} \leq 5.9$ and $\varepsilon \beta_{p \text { dia }} \leq 1.6$ were created in TFTR, surpassing an apparent limiting value of $\varepsilon \beta_{p}$ dia $\leq 0.7$ previously observed in TFTR supershots. ${ }^{13.14}$ Here, $\beta_{p}$ dia $\equiv 2 \mu_{o}\left\langle p_{\perp}\right\rangle \mid<\left\langle B_{p}>>2\right.$, where $\left\langle p_{\perp}\right\rangle$ is the volume average of the transverse plasma pressure and $\left\langle<B_{p}\right\rangle>$ is the line average of the poloidal magnetic field taken over the outer flux strface. The inverse aspect ratio, $\varepsilon \equiv a / R_{p}$, with the minor radius $a$ defined as one half of the midplane width and $R_{p}$ defined as the area averaged major radius. The Troyol ${ }^{15}$ normalized diamagnetic beta, $\beta_{N d i a} \equiv 10^{8}<\beta_{i \perp}>a B_{0} / I_{p}$, reached 4.7. For comparison, TFTR supershots had previously reached values of $\beta_{N \text { dia }} \leq 2.7 .16 \mathrm{Here}, B_{0}$ is the vacuum toroidal field at $R_{p}$. Fig. 1 , which shows $\varepsilon \beta_{p}$ dia as a function of $q^{*} \equiv 5\left(\alpha^{2} B_{0} / R_{p} I_{p}\right)\left(1+\kappa^{2}\right) / 2$, illustrates how the high $\beta_{p}$ plasmas extend the range of supershot operation in TFTR. Here, $x$ is the plasma elongation. As $\varepsilon \beta_{p}$ dia is increased to a value of approximately 1.25 , the plasma which is initially limited on the inside wall makes a transition to a diverted plasma, the boundary being defined by a naturally occuring separarrix with a poloidal fie!d null on the inboard side. At the larger values of $q^{*}$, the value of $\varepsilon \beta_{p}$ dia is limited by the separarrix moving further into the plasma minor radius. At the smaller values of $q^{*}$ the plasmas encounter a $\beta$ limit, but with a value of $\beta_{N}$ much larger than the limit of 3.0 originally proposed by Troyon. ${ }^{15}$

These plasmas were created in deuterium at relatively small $I_{p}(0.28-1.0 \mathrm{MA}$ during neutral beam heating), nominal $B_{0}=4.8 \mathrm{~T}$ and $R_{p}=2.45 \mathrm{~m}$. Separatrix limited discharges were created with two types of $I_{p}$ time histories, one in which $I_{p}$ was held constant and another in which $I_{p}$ was decreased, or ran:ped down, before the start of neutral beam injection. In the latter case, an ohmic plasma was formed with $i_{p}$ in the range $0.85-1.75 \mathrm{MA}$ and held for about $1 \mathrm{~s}$. The plasma current was then decreased rapidly at $-2.5 \mathrm{MA} / \mathrm{s}$ to a pedestal value in the range $0.3 \cdot 1.0 \mathrm{MA}$. The maximum ratio of initial to pedestal $I_{p}$ was abour 2.5 . In some discharges, beam injection was started before $I_{p}$ had been fully decreased to the pedestal value. The largest values of $\varepsilon \beta_{p}$ dia and $\beta_{N \text { dia }}$ were obtained in discharges in which $I_{p}$ was ramped down. Neui:-l beam heating, utilizing 
tangential injection of deuterium, usually began with co-injection only. Subsequently, counterinjected beams were added to provide nearly bal iced co and counter injection at $18-26 \mathrm{MW}$ during the high $\varepsilon \beta_{p}$ steady state. Line-averaged iarget densities were in the range $(1-3) \times 10^{19} \mathrm{~m}^{-3}$ and typically increased to $(3-6) \times 10^{19} \mathrm{~m}^{-3}$ during the auxiliary heating phase.

Waveforms illustrating the $I_{p}$ ramp-down and separatrix formation are shown in Fig. 2. An ohmic plasma was initially formed with $I_{p}=0.85 \mathrm{MA}$ (Fig. 2a). The plasma current was ramped down and held approximately constant at $0.4 \mathrm{MA}$ during the neutral beam hearing phase. In this particular discharge, $I_{p}$ decreased at a small rate $(-0.05 \mathrm{MA} / \mathrm{s})$ after the fast $I_{p}$ ramp-down had been completed. This was caused by the finite ability of the plarma control system to hold $I_{p}$ at an exactly programmed value while other plasma quantities, particularly $\beta_{p}$, were changing rapidly. The voitage associated with this slow decrease in $I_{p}$ is approximately $-0.25 \mathrm{~V}$, which is a small fraction of the $-1.5 \mathrm{~V}$ surface voltage measured during the high $\beta_{p}$ phase of the discharge.

Fig. 2b shows the evolution of $\beta_{p}$ dic and $A \equiv \beta_{p}$ eq $+l_{i} / 2$, with $l_{i}$ being the plasma internal inductance. At maximum stored energy, this discharge attained values of $\varepsilon \beta_{p}$ dia $=1.43$ and $\beta_{N \text { dia }}=3.4$ with $q^{*}=8.5$. As a result of the tangential beam injection, these discharges are anisotropic and $\beta_{p e q} \equiv\left(\beta_{p} \|+\beta_{p \perp}\right) / 2$ is larger than $\beta_{p d i a} \equiv \beta_{p \perp}$. The calculated ratio of $\beta_{p \mid l} / \beta_{p \perp}$ varies throughout the beam heating phase. Modeling of the discharge shown in Fig. 2 using the TRANSP code ${ }^{17}$ indicates that the ratio $\beta_{p} \mid / / \beta_{p \perp}$ reaches a maximum value of 1.65 that occlus $100 \mathrm{~ms}$ after the start of beam injection. This ratio decreases to 1.15 by the end of the beam injecrion.

Fig. 2c shows the evolution of the poloidal field measured at the midplane on the inboard side of the TFTR vacuum vessel. As $I_{p}$ is ramped down, and $\beta_{p}$ increases, the midplane poloidal field decreases and eventually becomes negative, indicating that the separatrix has crossed the roil position and moved into the vacuum vessel. The separarrix limited discharge is sustained unil the end of the beam heating phase. Fig. $2 \mathrm{~d}$ shows the $H_{\alpha}$ emission, viewed along the plasma midplane $\left(0^{\circ}\right)$. As the separatrix enters the vacuum vessel, and the divertor $x$-point moves into the 
plasma, the $H_{\alpha}$ emission at $0^{\circ}$ drops to a low level and remains low throughout the separatrix limited phase.

Additional details of the $H_{\alpha}$ emission signatures characteristic of the separatrix limited plasmas in TFTR are shown in Fig. 3. Here, the evolution of the plasma boundary from the discharge shown in Fig. 2 is reconstructed from a magnetic analysis code which uses external magnetic measurements and models the plasma current distribution as a collection of current filaments. ${ }^{18,19}$ Included in the figure are the $H_{\alpha}$ emission time histories from four chotds viewing different poloidal angles as shown. While the $H_{\alpha}$ emission shows some fluctuation, no large scale magnetohydrodynamic (MHD) modes or significant loss of plasma stored energy is observed to correlate with this activity. At $2.5 \mathrm{~s}$, the plasma is essentially circular and limited on the inner belt limiter. At $2.7 \mathrm{~s}$, the separativ is entering the vacuum vessel, the plasma becomes more oblate, and $H_{\alpha}\left(0^{\circ}\right)$ drops. There is a similar drop in the $H_{\alpha}$ emission at $7.5^{\circ}$ somewhat later in time as the $x$-point moves further into the vessel and the divertor strike points move to greater poloidal angles. This progression of the strike points eventually ceases as the equilibrium is reached at approximately $2.9 \mathrm{~s}$, and subsequently $H_{\alpha}\left(14^{\circ}\right)$ remains at a large value. The chord at $23^{\circ}$ being outside of the range of the strike point, exhibits a more standard emission trace. This evolution of the inboard $x$-point has also been observed using a visible-light camera that rangentially views the inside of the TFTR vacuum vessel.

A subset of the separatrix limited equilibria have been modeled using a free-boundary equilibrium code 20 based on the technique of Lao, and co-workers 21 that uses external magnetic measurements plus measurements of the local intemal poloidal field from polarimetry of emission from injected Li pellets. ${ }^{22}$ Data from 14 similar discharges were used to calculate the mean and standard deviation of the measurements. Note that the equilibrium reconstruction assumes that the measured errors are statistically independent and that the pressure is isotropic. Fig. 4 shows the reconstructed poloidal field profile fitted to the measured internal poloidal field data, and the poloidal flux contours for the least squares "best fit" equilibrium. This technique provides a measurement of the $q$ profile. For the 0.3 MA constant $I_{p}$ discharge shown in Fig. 4 , 
$A=5.1 \pm 0.3, \beta_{p} e q=1.38 \pm 0.12$ and $q_{0}=1.6 \pm 0.55$. This is in good agreement with $\Lambda=5.3 \pm 0.5$ obcained from filament code modelling. The large calculated Shafranov shift of the magnetic axis agrees with the axis position inferred from soft $\mathrm{x}$-ray measurements. Measurements of the electron temperature, $T_{e}$, density, $n_{e}$, and ion temperature, $T_{i}$, also exhibit this large outward axis shift. Peak $T_{i}=24 \mathrm{keV}$ and $T_{e}=8.5 \mathrm{keV}$ ( $T_{e}$ measured by Thomson scattering) have been achieved in these high $\beta_{p}$ TFTR plasmas.

\section{STAB:LITY AND $\beta$ LIMIT}

Values of $\varepsilon \beta_{p \text { dia }}>1.5$ have been reached in discharges in which $I_{p}$ was ramped down as well as in plasmas in which $J_{p}$ was held constant. At values of $q^{*} \geq 10\left(\beta_{N}\right.$ dia $\left.\leq 2.7\right)$, the maximum value of $\varepsilon \beta_{p \text { dia }}-1.6$ attained in these plasmas appears to be due to a limit imposed by the approach of the separarrix. At these large values of $q^{*}$, the maximum value of $\beta_{N \text { dia }}$ attained is due to the constraint on $\varepsilon \beta_{p}$ dia and is not associated with disruption or a soft decay in $\beta$ due to plasma instability.

The maximum value of $\beta_{N}$ dia reached in the high $\beta_{p}$ TFTR discharges exceeds that of previous TFTR supershot discharges by a factor of about 1.75. The largest values of $\beta_{N}$ dia were obtained in discharges in which $I_{p}$ was ramped down. This is illustrated in Fig. 5, where for a subset of the high $\beta_{p}$ database, $\beta_{N \text { dia }}$ is plotted as a function of the plasma current ramp ratio, $F_{I_{p}}$, defined as the ratio of $I_{p}$ before the ramp-down, to $I_{p}$ during the neutral beam heating phase. For example, the discharge illustrated in Fig. 2 has $F_{I_{p}}=2.2$. The subset excludes some constant $I_{p}$ discharges for clarity. No disruptions or large scale MHD activity were observed for high $\beta_{p}$. constant $I_{p}$ plasmas that had $1 \leq \beta_{N \text { dia }} \leq 2.3$. Relatively few disruptions were encountered for ali plasmas with $\beta_{N \text { dia }} \leq 3.6$. Above this value, the fraction of discharges ending in disruption increased dramatically. Many of these discharges disrupted after $\beta$ had reached saturation, indicating that profile relaxation toward an unstable state may have besn the cause of disruption. 
The disruptions at high $\beta_{N}$ were fast (on an ideal MHD timescale), and showed no clear precursors. Soft $\beta$ collapse was also observed in high $\beta_{N}$ discharges with $q^{*} \leq 10$. Analysis of the Mimov signal phase shows that the dominant mode is $m / n=2 / 1$, where $m$ and $n$ are the poloidal and toroidal mode numbers, respectively. The $m / n=3 / 2$ mode usually accompanies this mode, but at a lower amplitude. The onset of MHD activity leading to a $\beta$ collapse frequenty occured in discharges that had a larger fraction of co-injected beam power than counter-injected. Sawtooth activity was generally absent from the high $\beta_{p}$ discharges except those with the largest values of $I_{p}$ $(0.85$ - 1.0 MA).

Al larger values of $I_{p} \geq 0.8 \mathrm{MA}$, and at moderate values of $\varepsilon \beta_{p \text { dia }} \lesssim 1$, the discharges have been observed to make a transition into the limiter $\mathrm{H}$-mode ${ }^{23}$. This transition occurs more easily in discharges in which $I_{p}$ is ramped down. ${ }^{24}$ The limiter Hi-mode in TFTR is accompanied by edge localized modes (ELMs) which appear to cause $\beta$ saturation or degradation. $A$ transition to the limiter $\mathrm{H}$-mode generally does not occur at large $q^{*} \geq 10$ and large $\varepsilon \beta_{p}$ dia $\geq 1$.

The enhanced plasma stability, indicated by the achievement of increased values of $\beta_{N \text { dia }}$ when $I_{p}$ is ramped down, appears to be associated with the peaking of the plasma current profile, as shown by the increased value of $l_{i}$, during the high $\beta_{p}$ phase of the discharges. Fig. 6 shows the maximum value of $\beta_{N}$ dia as a function of $l_{i} / 2$ for a subset of the high $\beta_{\rho}$ equilibria analyzed by the TRANSP code; data for some supershot discharges is also shown. Here, $l_{i} \equiv\left\langle B_{p} 2 / 2 \mu_{0}\right\rangle\left\langle\left\langle B_{p}^{2} / 2 \mu_{0}\right\rangle_{d v a}\right.$, where $\left\langle B_{p}{ }^{2}\right\rangle_{d v a}$ is the differential yolume average of $B_{p}{ }^{2}$ over the outermost flux surface. Cases in which $I_{F}$ was ramped up have smaller values of $l_{i}$ while those in which $I_{p}$ was ramped down have larger values of $l_{i}$. The plasma current profile peakedness changes in response to the programmed plasma current and high $\beta_{p}$ equilibrium effects for each discharge. During $I_{p}$ ramp-down, the surface voltage reverses in order to decrease the plasma current. TRANS ${ }^{-}$Jde analysis of the current profile evolution shows a reduction, or in some cases, a reversal of the plasma current in the outer $1 / 3$ of the plasma. The $I_{p}$ ramp-down causes the edge $q$ to rise and $l_{i}$ to increase. A further increase in $l_{i}$ occurs as the high $\beta_{p}$ state is reached. Later 
in the high $\beta_{p}$ phase, $l_{i}$ generally decreases as the plasma current is resistively redistributed and as the bootstrap current fraction increases.

In addition, Fig. 6 shows the trajectory of :wo different discharges, one that encounters disruption, and another that does not. In both cases, neutral beam beating commences when $\beta_{N}$ dia begins to increase. The point of completion of the $I_{p}$ ramp-down in each discharge is indicated in the figure. For the trajectory marked by label a) in Fig. $6, I_{p}$ was ramped down from $0.85 \mathrm{MA}$ to $0.4 \mathrm{MA}$. The $\beta_{N \text { dia }}$ increases throughout the discharge, whereas $l_{i}$ first increases and subsequently decreases as described above, leading to disruption. For trajectory b), $I_{p}$ was ramped down from 1.0 MA to $0.7 \mathrm{MA}$. The $\beta_{N}$ dia initially increases as $l_{i}$ increases, but $\beta_{N}$ dia subsequently decreases coincident with a decrease in $l_{i}$. This plasma does not terminate in disruption but rather a soft $\beta$ decay leads to the reduction in $\beta_{N}$ dia. Neutral beam heating terminates as $\beta_{N \text { dia }}$ and $I_{i}$ are decreasing. In other high $\beta_{p}$ cases, $\beta_{N \text { dia sacurates and remains large }}$ until the end of the beam pulse.

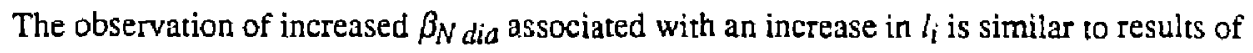
experiments performed on the DIII-D tokamak. ${ }^{25}$ This observation does not appear to be machine dependent, since the TFTR experiments were performed in a circular vacuum vessel with oblate plasmas $(\kappa \sim 0.7)$ and $I_{n}$ in the range $0.08<I_{n}<0.3$, where $I_{n} \equiv I / a B_{0}(\mathrm{MA} / \mathrm{m} / \mathrm{T})$, compared with elonga red plasmas $(\kappa \leq 1.9)$ and $1.0<I_{n}<1.4$ in DHI-D.

High- $m$ ballooning analysis of these discharges was performed on both the free boundary equilibria reconstructed from external and internal magnetic field data described earlier and equilitria generated using profile and outer boundary information from the TRANSP code. The results show that these plasmas are in the first region of stability to high- $n$ modes. Fig. 7 shows the stability results for an equilibrium constructed from TRANSP calculated profiles for a plasma in which $I_{p}$ was ramped down from 0.85 to $0.4 \mathrm{MA}$. The $q_{0}$ is calculated to be 1.1 for this particular equilibrium. The plasma pressure gradient, $p^{\prime}(\psi)$ is plotted as a function of a minor radial flux coordinate, $\sqrt{\left(\Psi-\Psi_{0}\right) /\left(\Psi_{a}-\Psi_{0}\right) \text {, }}$ (subscripts "a" and " 0 " correspond to the values at the plasma edge and magnetic axis, respectively), where $\psi$ is the poloidal flux. Pressure 
gradients which lie inside the shaded region are unstable. Those which lie below are stable in the first stability region, while those which lie above are in the second stability region. The equilibrium $p^{\prime}(\varphi)$ is in the first stable region in the plasma core, and lies on the first region boundary in the outer portion of the plasma. The stability of these plasmas on the outermost flux surfaces is uncertain, since the error associated with the $p^{\prime}(\psi)$ profile is of the order of the width of the unstable region at the plasma edge. Note that the beam particle pressure gradient is inciuded in the scalar pressure used for these equilibrium and stability calculations. The beam component of the pressure constitutes $58 \%$ of the total pressure on axis in the equilibrium in Fig. 7.

\section{ENERGY CONFINEMENT}

Energy confinement times of greater than 3 times L-mode values have been obtained in these high $\beta_{p}$ plasmas, similar to the enhancement reached in supershot plasmas. Fig. 8 shows $\tau_{E}$ normalized to that computed from the ITER 89-P energy confinement scaling relation 26 as a function of $\varepsilon \beta_{p}$ dia for a subset of the high $\beta_{p}$ database. There is a general increase in the confinement enhancement as $\varepsilon \beta_{p}$ dia increases, and p'astras in which $I_{p}$ is ramped down have the largest enhancement factors. Note that the confinement time data was taken at the time of maximum transverse stored energy, and $\tau_{E} \equiv E_{\text {cot }} / P_{\text {beam }}$, where $E_{\text {tot }}$ is the plasma stored energy and $P_{\text {beam }}$ is the beam power. The ohmic power, Potmic, is small for these cases. The ratio $P_{\text {ohmic }} / P_{\text {beam }} \leq 0.06$ at the largest $I_{p}$ and is usually much smaller at lower $I_{p}$. Absolute values of $\tau_{E}$ reach $130 \mathrm{~ms}$ in these plasmas. Values of $E_{10 t}$ of about $2.5 \mathrm{MJ}$ have been attained in plasmas with $I_{p}=0.83 \mathrm{MA}$. The high $\beta_{p}$ plasmas generally show an improvement in the absolute value of $\tau_{E}$ as $I_{p}$ is increased.

A significant improvement in $\tau_{E}$ is observed in plasmas in which $I_{p}$ was ramped down to a speciried value, compared to equivalent discharges in which $l_{p}$ was held constant. For example, the discharge shown in Fig. 2, where $I_{p}$ was decreased from $0.85 \mathrm{MA}, 0.4 \mathrm{MA}$ before neutra! 
beam injection at $P_{\text {beam }}=19 \mathrm{MW}$, had $\tau_{E}=45 \mathrm{msec}$. A discharge with the same heating power and constant $I_{P}=0.4 \mathrm{MA}$ had $\tau_{E}=28 \mathrm{msec}$. By starting beam injection $100 \mathrm{msec}$ before $I_{p}$ had been fully ramped down from $0.85 \mathrm{MA}$ to $0.4 \mathrm{MA}, \tau_{E}=64 \pm 5 \mathrm{msec}$ was attained at $P_{\text {beam }}=17 \mathrm{MW}$, more than doubling the value obrained at constant $l_{p}$. A similar relative increase in $t_{E}$ has been observed in other experiments on TFTR ${ }^{27}$ and ASDEX ${ }^{28}$ in which $I_{p}$ was varied during the neutral beam injection phase of the discharge.

\section{NON-INDUCTIVE CURRENTS AND CURRENT PROFILE CONTROL}

The high $\beta_{p}$ plasmas in TFTR have low collisionality for both ions and electrons. Under these conditions, a significant amount of bootstrap current should contribute to $l_{p}$. Shown in Fig. 9 is the time evolution of $I_{p}$, surface voltage, and $\beta_{p}$ dia for a discharge in which $\delta_{p}$ was ramped down from $1.0 \mathrm{MA}$ to $0.6 \mathrm{MA}$. The parameters $v_{e}^{*}$ and $v_{i}^{*}$ for this discharge at $3.9 s$ are 0.1 and 0.02 at one half of the minor radius. Includer with the time history waveforms are the noninductive current components of $I_{p}$ and the surface voltage calculated by TRANSP. As the current is decreased before the beam injection, the surface voltage swings negative, removing $0.29 \mathrm{~Wb}$ of poloidal flux from the plasma between 3.0 and $3.25 \mathrm{~s}$. The plasma current profile is primarily affected in the outer $1 / 3$ of the plasma, and the classical time constant associated with this change is about $0.3 \mathrm{~s}$. Since the co-injected beams are switched on first, there is initially a large fractiun of co-directed current driven by the beams. In this discharge, there is $37 \%$ more counter-injected power than co-injected power during the high $\beta_{p}$ phase. Since the co-injected beamlines drive current more efficiently than the counter beamlines due to orbit effects, this produces no net beam driven current. The bootstrap cutrent is calculated to be $65 \%$ of the total $I_{p}$ in this case. Similar results were obtained for discharges with balanced neutral beam injection. In these calculations, any potential contribution to the bootstrap current due to the anisotropic beam-particle pressure 
gradient has been neglected. The beam-particle pressure constitutes approxi nately $45 \%$ of the total plasma pressure in the plasma core at the end of the discharge.

In both constant current, and $I_{p}$ ramp down casss, there is a significant reversal of the surface voltage during the high $\beta_{p}$ portion of the discharge, as shown in Fig. 9. The larges: bootstrap current fractions were calculated io occur in $I_{p}$ ramp down cases. The surface voltage remains negative for the duration of the beam puls, relaxing fron less than $-1 \mathrm{~V}$ to about $-0.2 \mathrm{~V}$. A total of $0.35 \mathrm{~Wb}$ of poloidal tlax was measured to be removed from the plasma between 3.4 and $4.0 \mathrm{~s}$. The classical tine constant associaied with this change is about one second.

\section{NEUTRON PRODUCTION AND FUSION POINER GAIN}

Neutron production in the high $\beta_{p}$ discharges at the larger values of $I_{p}(0.85-1.0 \mathrm{MA})$ is comparable so TFTR supersho: performance. Shown in Fig, 10 is the maximum neutron rate, $\bar{s}_{n}$,

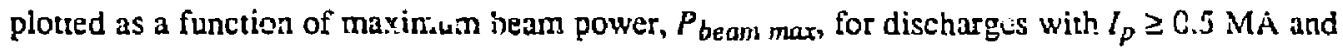
$\varepsilon \beta_{\rho \text { dia }} \geq 0.7$. Also shown is the nominal supershot neutron production parformance as a function of beam power. ${ }^{29}$ Discharges that have $S_{n}$ within $20 \%$ of this curve have $0.75 \leq \varepsilon \beta_{p}$ dia $\leq 1.12$. At a plasma current of about $0.85 \mathrm{NA}$, neutron rates of $(1.5-1.9) \times 10^{16} \mathrm{sec}^{-1}$ have been achieved during the discharge and were sustained for $0.3-0.4 \mathrm{sec}$ until neutral beam heating was terminated. For example, $S_{n}=1.7 \times 10^{16} \mathrm{sec}^{-1}$ was reached at $l_{p}=0.82 \mathrm{MA}, E_{t o t}=2.3 \mathrm{MJ}$, $\varepsilon \beta_{p \text { dia }}=0.89$, and $P_{\text {beam } \max }=19 \mathrm{MW}$. The corresponding devterium - deuterium fusion power gain, $Q_{D D}$, is $1.1 \times 10^{-3}$. At $I_{p}=0.97 \mathrm{MA}, S_{n}=2.6 .3 \times 10^{16} \mathrm{sec}^{-1}$ was reached tiansiently with $E_{l o t}=2.8 \mathrm{MJ}, \varepsilon \beta_{p \text { dia }}=0.85$, and $r_{\text {beam } \max }=24 \mathrm{MW}$, yielding $Q_{D D}=1.3 \times 10^{-3}$. This $Q_{D D}$ is $70 \%$ of the best value achieved in TFTR, obtained in a diccharge that had $I_{p}=1.9 \mathrm{MA}$.

At a fixed plasma current, there is a large incre ise in the neutron production but only a small gain in $Q_{D D}$ in high $\beta_{p}$ discharges as corrpared to supershots where the domains of these discharges overlap. At $I_{p}=0.8 \mathrm{MA}$ and $P_{\text {beam max }}=14 \mathrm{MW}$, supershot discharges yield $S_{n}=1.0$ 
$x 10^{16} \mathrm{sec}^{-1}$. At $I_{p}=1.0 \mathrm{MA}$ and $P_{\text {beam } \max }=18 \mathrm{MW}, S_{i n}=1.6 \times 10^{16} \mathrm{sec}^{-1}$ has been reached. The high $\beta_{p}$ discharge mentioned above produced more neutrons than that achieved in the $I_{g}=1 \mathrm{MA}$ supershot by greater than a factor of 1.6. This increase in the neutron rate comes about from the larger beam power that can be toierared at a given $I_{p}$ in the high $\beta_{p}$ discharges before a plasma disruption occurs. To obtain $S_{n}$ equal to that of the high $\beta_{p}$ discharge with $I_{p}=1 \mathrm{MA}$, the plasma current in the supershot case needs to be raised to about $1.35 \mathrm{MA}$. The neural beam heating power for this supershot wet with equivalent $S_{n}$ would be $22 \mathrm{MW}$, slightly less than was used in the $I_{p}=1 \mathrm{MA}$ high $\beta_{p}$ case. Note that $Q_{D D}$ is $1.2 \times 10^{-3}$ in the $I_{p}=1 \mathrm{MA}$ supershor discharge, which is essentially equal to the value reached in the high $\beta_{p}$ discharge at the same plasma current bur at larger beam power.

\section{SUMMARY AND DISCUSSION}

The operating range of TFTR plasmas has been expanded to include plasmas with $\varepsilon \beta_{p}$ dia up to 1.6 and $\beta_{N}$ dia up to 4.7 . The range of $l_{p}$ during neutral beam injection was $0.28 \mathrm{MA} \leq I_{p} \leq 1.0 \mathrm{MA}$. At $\varepsilon \beta_{p}$ tia above 1.25 , a natural inboard poloidal field null is observed to enter the vacuum vessel. The high $\beta_{p}$ separatrix forms a stable, diverted plasma with an oblate shape $(\kappa \sim 0.7)$. The maximum value of $\varepsilon \beta_{p}$ dio for $q^{*} \geq 8$ is apparently due to an equilibrium limit, as the x-point moves further into the plasma minor radius. The largest values of $\varepsilon \delta_{p}$ dia and $\beta_{N \text { dia }}$ are obtained when $I_{p}$ is ramped down. Stable operation at large $\beta_{N}$ dia is associated with increased plasma internal inductance, or peaked current profile. The only active current profile control in these discharges is provided by the ohmic heating tansformer, acting as a source of anti-current drive during the $I_{p}$ ramp dow:n and high $\beta_{p}$ phases of the discharges. Non-inductive currents also reshape the current profile, with the bootstap current calculated to comprise a significant component. The bootstrap current is calculated to constitute as much as $65 \%$ of the total current in these plasmas. The energy confinement . . ierties of these discharges "re significantly enhanced 
over L-mode prediction. Energy confinement times greater than 3 times those expected from the ITER-89P scaling relation have been reached. This enhancement factor appears to increase as $\varepsilon \beta_{p \text { dia }}$ increases up to the equilibrium limit. Absolute values of $\tau_{E}$ and $E_{\text {fot }}$ have reached $130 \mathrm{~ms}$ and $2.8 \mathrm{MJ}$, respectively. At a given neutral beam power, discharges in which $I_{p}$ was ramped down to a specified value had substantially larger $\tau_{E}$ than in discharges in which $I_{p}$ was held constant. The neutron production of the high $\beta_{p}$ plasmas with the largest $I_{p}$ is comparable to that of standard supershot performance at a given neutral beam power level,-but at significantly reduced plasma current. The $Q_{D D}$ has reached $1.3 \times 10^{-3}$ in a plasma with $I_{p}=1 \mathrm{MA}$ and $\varepsilon \beta_{p}$ dia $=0.85$.

This demonstration of successful plasma operation near the equilibrium limit, and at large values of $\beta_{N \text { dia }}$ with proper plosma current profile control, supports high performance fusion reactor designs, such as ARIES and the JAERI SSTR, and future tokamak experiments operating at reduced $I_{p}$. The present experiments also point out several important considerations for $t$. . high $\beta$ tokamak designs. The first is inclusion of current drive to provide not only steady-state operation, but also current profile shape control. In the present experiments, the ohmic heating transformer only provides control of the plasma current density in the outer portion of the plasma. A technique such as lower hybrid current drive, which can drive current efficiently near the plasma edge may therefore be sufficient to provide and sustain a curreut profile shape leading to a stable plasma exhibiting enhanced $\beta_{N}$ performance. Since this system would be operating in a plasma with reduced $I_{p}$ and only in a region of relatively small current density, the power requirements could be kept low. Another key consideration is the role of the bootstrap current, which will drive co-directed plasma curient, and hence may reduce the externally driven current required for steadystate operation. However, the bootstrap effect will broaden the current profile and reduce $l_{i}$ which, in the present experiments, is assuciated with a reduction of the $\beta_{N}$ at which the tokamak can operate in a stable fashion. The competing nature of these two effects needs to be carefully considered in high $\beta$ tokamak designs that would operate in the first stability region. A more detailed physics analysis of the improved stability and confinement of these high $\beta_{p}$ dischar, es is presently underway. 


\section{Acknowledgements}

The authors would like to thank M. W. Phillips of Grumman Corporation for making available the EQGRUM and STBAL equilibrium and stability codes used in the present analysis. We also thank Rob Goldston and Dale Meade for their encouragement, and the entire staff of the TFTR projest for providing a reliable and well diagnosed machine for these experiments.

This work was supported by US Department of Energy Contracts DE-FG02-89ER53297, DE-AC02-76-CHO-3073, and DE-FG02-90ERS4084. 
${ }^{1} \mathrm{~K}$. Tomabechi, and the ITER group, in Plasma Physics and Controlled Nuclear Fusion Research. Ploreadings of the 12th International Conference, Nice, 1988 (IAEA, Vienna 1989), Vol, 3. p. 215.

2J, Sheffield, J. Fusion Energy 4, 187 (1985).

${ }^{3}$ M.C. Zarnstorff, M.G. Bell, M. Bitter, R.J. Goldsten, B, Grek, R.J. Hawryluk, K. Hill, D. Johnson, D. McCune. H. Park, A. Ramsey, G. Taylor, and R. Wieland, Phys. Rey. Lert. 60, 1306 (1988).

${ }^{4}$ A.A. Galeev, Zh. Eksp. Teor. Fiz. 59, 1378 (1970) [Sov. Phys. JETP 32, 752 (1971)].

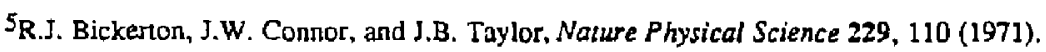

${ }^{6} \mathrm{~F}$. Najmabadi, R,W. Conn. and the ARIES design team, "The ARIES-I Tokamak Reactor Sudy -The Final Report." University of California Los Angeles report PPG-1323 (1990; T.K. Ma!י, E. Ibrahim. G. Emmerr, J.F. Santarius, and the ARIES Hesign team, Bull. Am. Phys. Soc. 35, 2131 (1990).

${ }^{7}$ M. Kikuchi, Nuclear Fusion 30, 265 (1990).

${ }^{8}$ R.J. Hawryluk, V. Arunasalam, M.G. BelI, M. Bitter, W.R. Blanchard, N.L. Bretz, R, Budny, C.E. Bush, J.D. Callen, S.A. Cohen, 3.K. Combs, S.L. Davis, D.L. Dimock, H.F. Dylia, P.C. Efthimion, L.C. Emerson, A.C. England, H.P. Eubank, R.J. Fonck, E.D. Fredrickson, H.P. Furth. G. Gammel, R.J. Goldston, B. Grek, L.R. Grisham, G.W. Hammer, W.W. Heidbrink, H.W. Hendel, K.W. Hill, E. Hinnov, S. Hiroe, H. Hsuan, R.A. Hulse, K.P. Jaehnig. D.L. Jassby, F.C. Jobes. D.W. Johnson, L.C. Johnson, R. Kaita, R. Kamperschroer, S.M. Kaye, S.J. Kilpatrick, R.J. Knize; H. KugeJ, P.H. LaMarche, B. LeBlanc, R. Little, C.H. Ma, D.M. Manus, D.K. Mansfield, R.T. McCann. M.P. McCarthy, D.C. McCune, K. McGuire, D.H. MeNeill, D.M. Meade, S.S. Medley, D.R. Mikkelsen, S.L. Milora, W, Morris, D. Mueller, V. Mukhovatov, E.B. Nieschmidt, J. O'Rourke, D.K. Owens, H.K. Park, N. Pomphrey, B. Prichard, A.T. Ramsey, M.H. Redi, A.L. Roquemore, P.H. Rutherford, N.R. Sauthoff, G. Schilling, J. Schivell, G.L. Schmidt, S.D. Scott, S. Sesnic, J.C. Sinnis, FJ. Stauffer, B.C. Stratton, G.D. Tait, G. Taylor, J.R. Timberlake, H.H. Towner, M. Ulrickson, V. Vershkov, S. Von Goeler, F. Wagner, R. Wieland, I.B. Wilgen. M. Williams, K-L. Wong, S. Yoshikawa, R. Yoshino, K.M. Young, M.C. Zamstorff, V.S. Zaveryaev, 
and S.J. Zweben, in Plosmo Physics and Controlled Nuclear Fusion :-search, Proceedings of the 11 th Intemational Confreance Kyoto, 1986 (IAEA, Vienna, 1987), Vol. 1, p. 51.

${ }^{9}$ A.V. Deniz, X.L. Li, and T.C. Marshall, Phys. Fluids 30, 2527 (1987).

${ }^{10}$ T.C. Simonen, M. Massuoka, D.K. Bhadra, K.H. Burrell, R.W. Callis, M.S. Chance, M.S. Chu, J.M. Greene, R.J. Groebner, R.W. Harvey, '. , . Hill, J. Kim, L. Lao, P.I. Petersen, G.D. Porter, H. St. John, B.W. Stallard, R.D. Stambaugh, E.J. Strait, and T.S. Taylor, shys. Rey, Lett, 61, 1720 (1988),

${ }^{11}$ A.W. Morris, R. Fitzpatrick, P.S. Haynes, T.C. Hender, J. Hugill, C. jilvester, and T.N. Todd, in Proceedings of the 77 ih European Conference on Controlled Fusion and Plasma Heating. Amsterdam (EPS, Petit-Lancy, Switzerland, 1990), Vol. 14B, part I. p. 379.

12S.C. Luckhardt, K.-1. Chen, S. Coda, J. Kesner, R. Kirkwood, B. Lane, M. Porkolab, and I. Squire, Phys. Rev. Letr. 62, 1508 (1989).

${ }^{13}$ J.D. Strachan, M. Bittcr, A.T, Ramsey, M.C. Zarnstorf, Y. Auunasalam, M.G. Bell, N.L. Bretz. R.Y. Budny, C.E. Bush, D.L. Davis, H.F. Dylla, P.C. Efthimion, R.J. Fonck, E.D. Fredrickson, H.P. Furth, R.J. Goldston, B. Grek, L R. Grisham, RJ. Hawryluk, W.W. Heidbrink, H.W. Hendel, K.W. Hill, H. Hsuan, K.P. Jaehnig, D.I. Jassby, F.C. Jobes, D.W. Johnson, L.C. Johnson, R. Kaita, J. Kamperschroer, R.J. Knize, T. Kozub, H. Kugel, B. LeBlanc, F. Levinton, P.H. LaMarche, D.M. Manos, D.K. Mansfield, K.M. McGuirc, D.H. MeNcill, D.M. Meade. S.S. Medley, W. Morris, D. Mucller, E.B. Nieschmidt, D.K. Owens, H.K. Park, J. Schivell, G. Schilling, G.L. Schmidt, S.D. Scott, S. Sesnic, J.C. Sinnis, F.J. Stauffer, B.C. Stratton, G.D. Tait, G. Taylor, H.H. Towner, M. Ulrickson, S. Von Goeler, R. Wieland, M.D. Williams, K-L. Wong, S. Yoshikawa, K.M. Young, and S.J. Zweben, Phys. Rev. Lelr. 58, 1004 (1987).

${ }^{14}$ K. McGuire, V. Arurasalam, C.W. Barnes, M.G. Bell, M. Bitter, H.-S. Bosch, N.L. Bretz, R. Budny, C.E. Bush, A. Cayallo, P.L. Colestock, S.L. Davis, D.L. Dimock, H.F. Dylla, P.C. Efthimion, A.B. Ehrhardt, R.J. Fonck, E.D. Fredrickson, R.J. Goldston, G.J. Greene, B. Grek, L.R. Grisham, G.W. Hammet, R.J. Hawryluk, H.W. Hendel, K.W. Hill, E. Hinnov, R.B. Howell, H. Hsuan, K P. Jaehnig, D.I. Jassby, F.C. Jobes, D.W. Johnson, L.C. Johnson, R. Kaita, S.I. Kilparrick, R.J. Knize, G. Kuo-Petravic, P.H. LaMarche, D.M. Manos, J. Manickam, D.K. Mansfield, R.T. McCann, M.P. McCarthy, D.C. McCune, D.H. McNeill, D.M. Meade, S.S. Medley, D.R. Mikkelsen, A. Miller, W. Morris, D. Mueller, E.B. Nieschmidt, D.K. Cwens, H.K. Park, N. Pomphrey, A.T. Ramsey, M.H. Redi, P.H. Roquemore, T, Saito. N.P. Sauttoff, G. 
Schilling, J. Schivell, G.L. Schmidt, S.D. Scott, J.C. Sinnis, J.E. Stevens, W. Stodiek, B.C. Stratton, G.D. Tuit, G. Taylor, J.R. Timberlake, H.H. Towner, M. Ulrickson, S. Von Goeler, R. Wieland, M. Williams, K-L. Wong, S. Yoshikawa, K.M. Young, M.C. Zarnstorff, and S.J. Zweben, Plasma Physics and Consrolled Fusion 30, 1391 (1988).

${ }^{15}$ F. Troyon, R. Gruber, H. Saurenmann. S. Semenzato, and S. Succi, Plasma Phys, and Cont. Fusion 26 1A, 209 (1984); Phys. Lett. 110A, 29 (1985).

16 M.G. Bell, V. Arunasalam, C.W. Bames, M. Bitter, H.-S. Bosch, N.L. Bretz, R. Budny, C.E. Bush, A. Cavallo, T.K. Chu, S.A. Cohen, F.L. Colestock, S.L. Davis, D.L. Dimock, H.F. Dylla, P.C. Efthimion, A.B. Ehrhardt, R.J, Fonck, E.D. Fredrickson, H,P. Furth, G. Gammel, R.J. Goldston, GJ. Greene, B. Grek, L.R. Grisham, G.W. Fammet, R.J. Hawryluk, H.W. Hendel. K.W. Hill, E. Hinnov, J.C. Hosca, R.B. Howell, H. Hsuan, R.A. Hulse, K.P. Jaehnig, A.C. Janos, D.L. Jassby, F.C. Jobes, D.W. Johnson, L.C. Johnson, R. Kaita, C. Kieras-Phillips, S.J. Kilpatrick, V.A. Krupin, P.H. LaMarche, W.D. Langer, B. LeBlane, R. Litcle, A.I. Lysojvan, D.M. Manos, D.K. Manstield, E. Mazzucato, R.T. McCann, M.P. McCarthy, D.C. McCune, K.M. McGuire, D.H. McNeilI, D.M. Meade, S.S. Medley, D.R. MikkeIsen. R.W. MoLley, D. Mueller, Y, Murakami, J.A. Murphy, E.B. Nieschmidt, D.K. Owens, H.K. Park. A.T. Ramsey, M.H. Redi, A.L. Roquemore. P.H. Rutherford, T. Saito, N.R. Sauthoff, G. Schilling, J. Schivell, G.L. Schmidt, S.D. Scott, J.C. Sinnis, J.E. Stevens, W. Stodiek, B.C. Stratton, G.D. Tait, G. Taylor, J.R. Timberlake, H.H. Towner, M. Ulrickson, S, Von Goeler, S. Yoshikawa, K.M. Young, M.C. Zarnsiorff, and S.J. Zweben, in Plasma Physics and Controlled Nuclear Fusion Research. Proceedings of the 12th International Conference Nice, 1988 ('AEA, Vienna, 1989), Vol. 1, p. 27.

${ }^{17}$ R.J. Goldston, D.C. M:Cune, H.H. Towner, S.L. Davis, R.J. Hawryluk, and G.L. Schmidt, J. Comput. Phys. 43, 61 (1981).

${ }^{18}$ D.W. Swain, and G.H. Neilson, Nucl. Fusion 22, 1015 (1982).

${ }^{19}$ L.L. Lao, H. St John, R.D. Stambaugh, and W. Pfeiffer, Nucl. Fusion 25, 1421 (1985).

20 M.E. Mauel, T.H. Ivers, H.Y. Che, D. Chen, D. Gates, T.C. Marshall, G.A. Navratil, J. Wang, D.S. Darrow, M. Ono, in Plosma Physics and Controlled Nuclear Fusion Research. Proceeciings of the 12,h International Conference Nice, 1988 (IAEA, Vienna, 1989), Vol. 1, p. 415.

${ }^{21}$ L.L. Lao, H. St. John, R.D. Stambaugh, A.G. Kellman, W. Peiffer, Nuclear Fusion 25, $16 \mathrm{I} 1$ (1985).

${ }^{22}$ E.S. Marmar, J.L. Terry, B. Lipshultz, and J.E. Rice, Rev. Sci. Instrum. 60, 3739 (1989). 
${ }^{23}$ C.E. Bush, R.J. Goldston, S.D. Scott, E.D. Fredrickson, K. McGuire, J. Schivell, G. Taylor. C.W. Bames, M.G Beli, R.L. Boivir, N. Bcelz, K. V. Budny, A. Cavallo, P.C. Efthimion, B. Grck. R. Hawryluk, K. Hill, R.A. Hulse, A. Janos, D.W. Johnson, S. Kilpatrick, D.M. Manos, D.K. Mansfield, D.M. Meade, H. Park, A.T. Ramsey, B. Stratton, E.J. Synakowski, H.H. Towner, R.M, Wieland, M.C. Zarnstorff, and S.J. Zweben, Phys. Rev. Lett, 65, 424 (1990).

${ }^{24}$ K. Toi, K. Kawahata, S. Morita, T. Watari, R. Kumazawa, K. Ida, A. Ando, Y, Oka, M. Sakamoto, Y. Hamada, K. Adati, R. Ando, T. Aoki, S. Hidekuma, S. Hirokura, O. Kaneko, A. Karita, T. Kawamoto, Y. Kawasumi, T. Kurada, K. Masaj, K. Narihara, Y. Ogawa, K. Ohkubo, S. Okajima, T. Ozaki, M. Sasao, K.N. Sato, 'T. Seki, F. Shimpo, H. Takahashi, S. Traahashi, Y. Taniguchi, and T. Tsuzuki, Phys, Rev. Letr. 64. 1895 (1990).

25E.J. Strait, J.R. Ferron, L.L. Lao, T.S. Taylor, M.S. Chu, F.J. Helton, W.L. Howl, A.G. Kellman, F. Lazarus, J.K. Lee, T.H. Osborne, R.D. S̈umbaugh, and A.D. Tumbull, Bull. Am. Phys. Soc. 34, 1939 (1989).

26P.N. Yushmanov, T. Takizuka, K.S. Riedel, O.J.W.F. Kardaun, J.G. Cordey, S.M. Kaye, D.E. Post, Nacl. Fusion 30, 1999 (1990).

${ }^{27}$ M.C. Zarnstorff, B. Grek, D.W. Johnson, D.K. Mansfield, E.S. Marn.ar, H.K. Park, A.T. Ramsey, J. Schivell, S.D. Scott, B.C. Stratton, E.J. Synakowski, G. Taylor, and J.L. Terry, Bull. Am. Phys. Soc. 35, 2108 (1990).

${ }^{28} \mathrm{H}$. Murmann, H. Zohm, and the ASDEX - and NI team, in Proceedings of the 17th European Conference on Conmalled Fusion and Plasma Heating, Amstendam (EPS, Petit-Lancy, Swizerland. 1990). Vol. 14B, part I, p. 54.

${ }^{29}$ D.L. Jassby, and the TFTR Group, Bull. Am. Phys. Soc. 35, 1917 (1990), submitted to Phys. Fluids $B$. 


\section{Figure Captions}

Fig. 1: $\varepsilon_{\beta} \beta_{r}$ dia for High $\beta_{p}$ discharges in TFTR plotted as a function of $q^{*}$. The high $\beta_{p}$ discharges have extended TFTR operation to larger values of $q^{*}, \varepsilon \beta_{p}$ dia $\leq 1.6$, and $\beta_{N \text { dia }} \leq 4.7$. Contours of $\beta_{N \text { dia }}$ appear as straight lines in this figure.

Fig. 2: Time history waveforms for a high $\beta_{p}$ discharge with $I_{p}$ ramp-down. Shown in this figure are a) the plasma current and neutral beam heating, b) $A$ and $\left.\beta_{p \text { dia }}, c\right)$ the poloidal field at the midplane, on the inboard side of the vacuum vessel, and d) the midplane $H_{\alpha}$ emission. As $\beta_{p \text { dia }}$ rises, a separatrix enters the vacuum vessel, as indicated by the reversal of the midplane poloijal field measured just outside the inhoard side of the vacuum vessel, and by a sharp drop in the midplane $H_{\alpha}$ emission.

Fig. 3: Evolution of the plasma outer boundary and $H_{\alpha}$ emission for the high $\beta_{p}$ discharge of Fig. 2. The plasma makes a transition from a circular discharge limited on the inner belt limiter, to an oblate separatrix limited discharge. A drop in the $H_{\alpha}$ emission is observed at $0^{\circ}$ and $7.5^{\circ}$ as the separanix enters the vessel and the divertor strike points move to greater poloidal angles.

Fig. 4: Free boundary equilibrium reconstruction of a $0.3 \mathrm{MA}$, constant $I_{p}$ discharge. Fig. 4a) shows the internal poloidal magnetic field measurements and the least squares "best fit" poloidal field profile reconstruction. Fig 4 b) shows the poloidal flux contours for the equilibrium. 
Fig. 5: Troyon normalized diamagnetic $\beta$ as a function of plasma current ramp ratio. The maximum value of $\beta_{N}$ dia increases as the plasma current ramp a atio inc.eases.

Fig. 6: Troyon normalized diamagnetic $\beta$ as a function of plasma internal inductance. The points represent the maximum $\beta_{N}$ dia atained for each discharge. The rajectory marked by label a) perains to a discharge in which $I_{p}$ was ramped down from $0.85 \mathrm{MA}$ to $0.4 \mathrm{MA}$. The trajectory marked by label b) pertains to a discharge in which $I_{p}$ was ramped down from $1.0 \mathrm{MA}$ to $0.7 \mathrm{MA}$. The maximum value of $\beta_{N \text { dia }}$ increases for discharges in which $l_{i}$ is increased.

Fig. 7: High-n ballooning stability for a high $\beta_{p}$ discharge in which $I_{p}$ is ramped down. The plas.ala pressure gradient is in the first region of hign-n balloonirg stability.

F: for high $\beta_{p}$ discharges. The largest enhancement factors uccur in plasmas in which $I_{p}$ was ramped down. The representative error bars shown arise from the uncertainty in the stored energy as calculated from magnetics medsurements.

Fig. 9: Calculated non-inductive current contributions to $I_{p}$. Shown in this figure are a) $I_{p}$ and the calculated non-inductive beam and bootstrap driven components of $\left.I_{p}, b\right)$ the measured and calculated plasma surface voliage, and $c$ ) the evolution of $\beta_{p \text { dic }}$ and neutral beam heating. The bootstrap current constitures up to $65 \%$ of $I_{p}$ for this discharge. The calculated surface voltage waveform is in good agreement with the measured waveform. 
Fig. 10: Maximum neutron rate as a function of maximum beam power for discharges with $I_{p} \geq 0.5 \mathrm{MA}$ and $\varepsilon \beta_{p}$ dia $\geq 0.7$. The curve describing the nominal neutron rate for TFTR supershots is superimposed for reference. Neutron production in high $\beta_{p}$ discharges with $I_{p} \geq 0.85 \mathrm{MA}$ is comparable to supershot discharges. 
Fig. 1

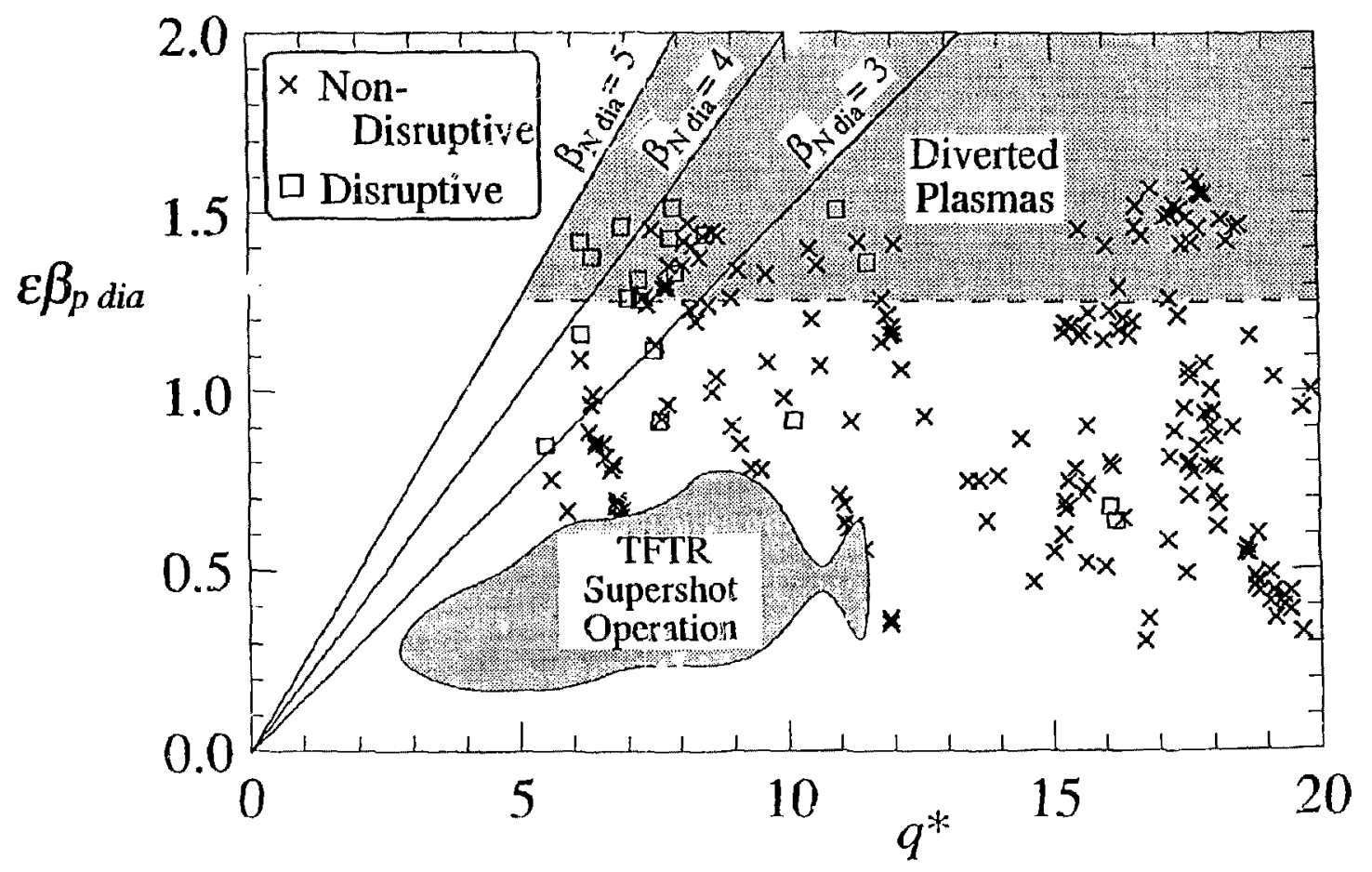


Fig. 2

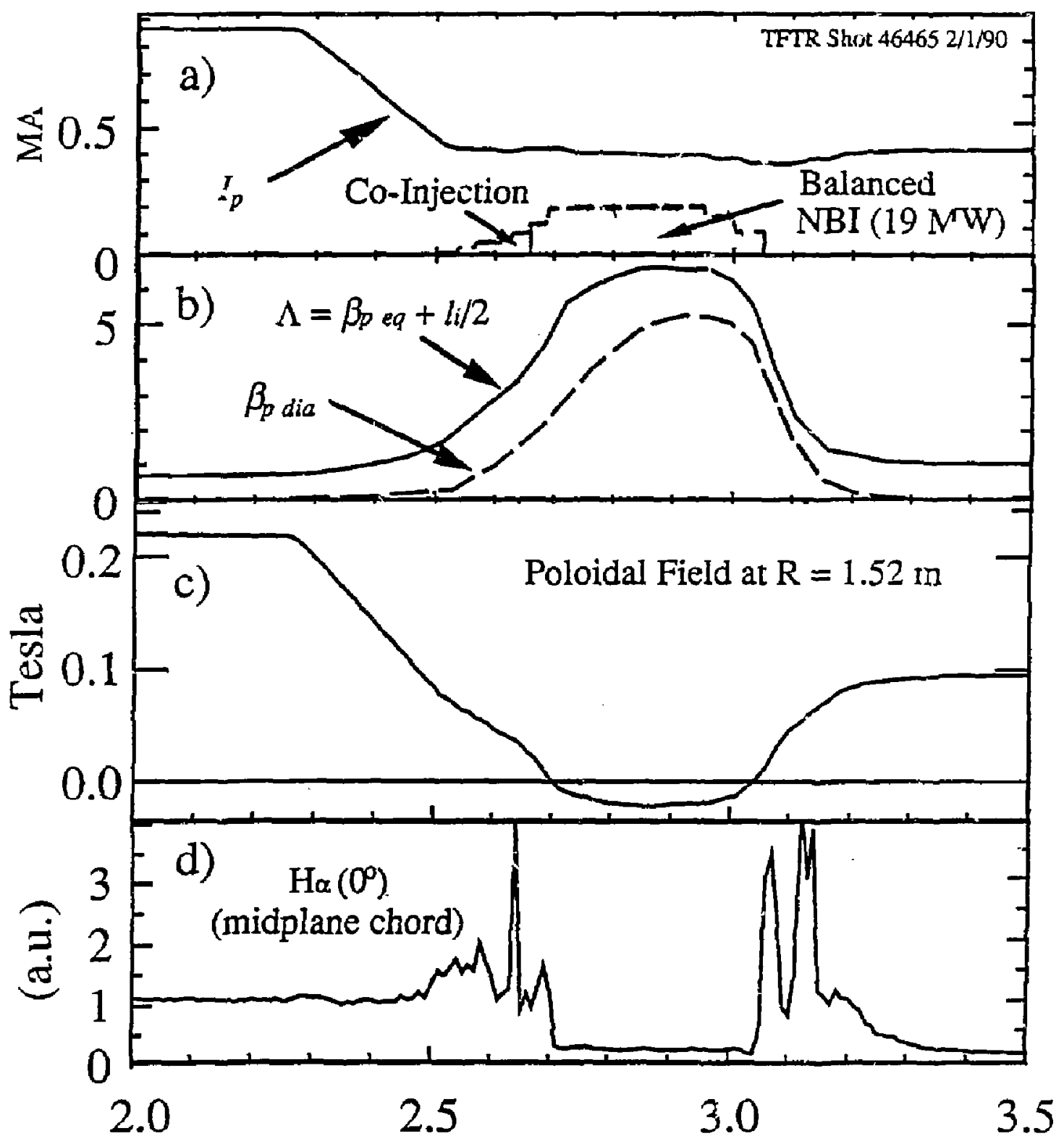

Time (s) 
Fig. 3
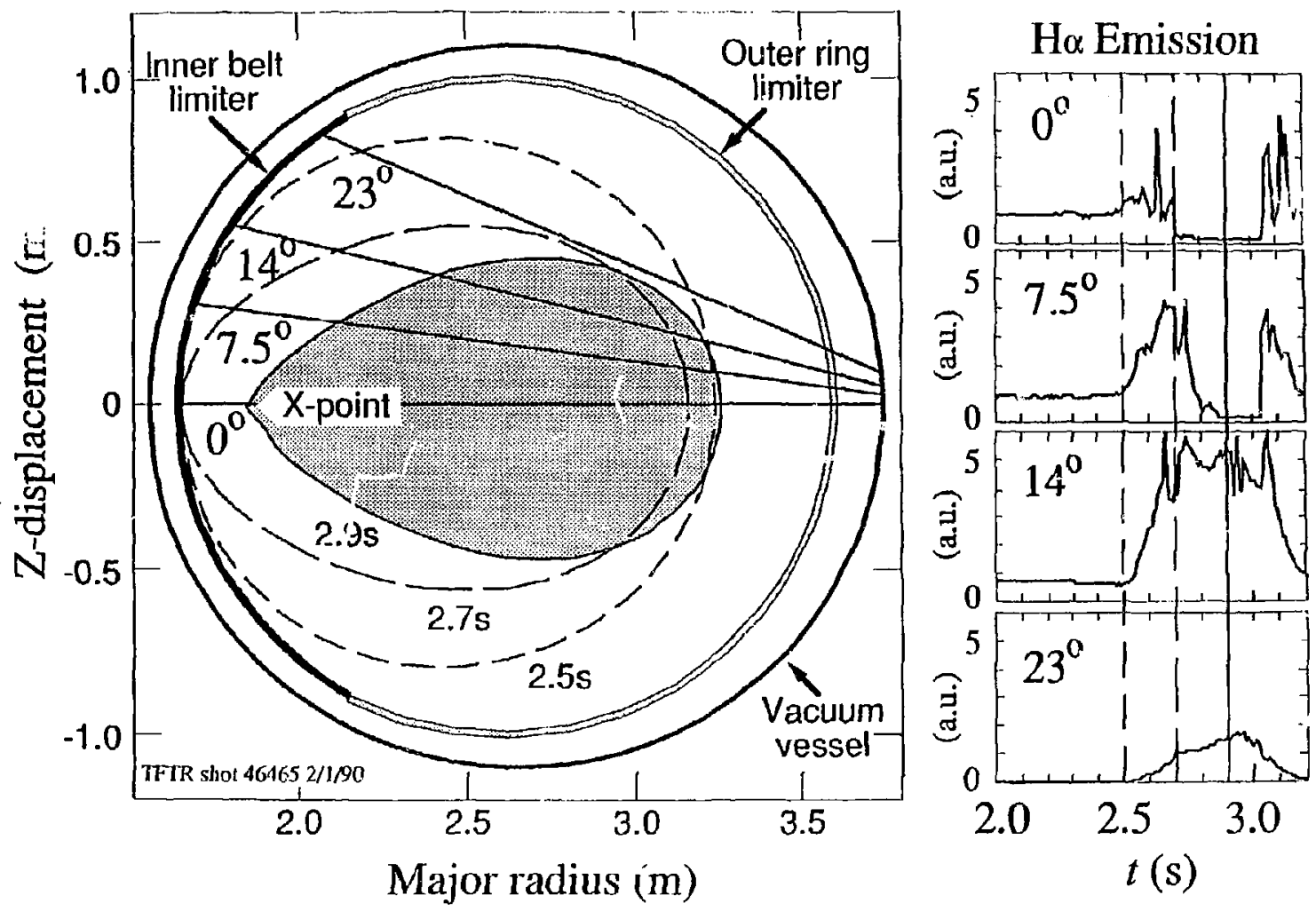
Fig. 4

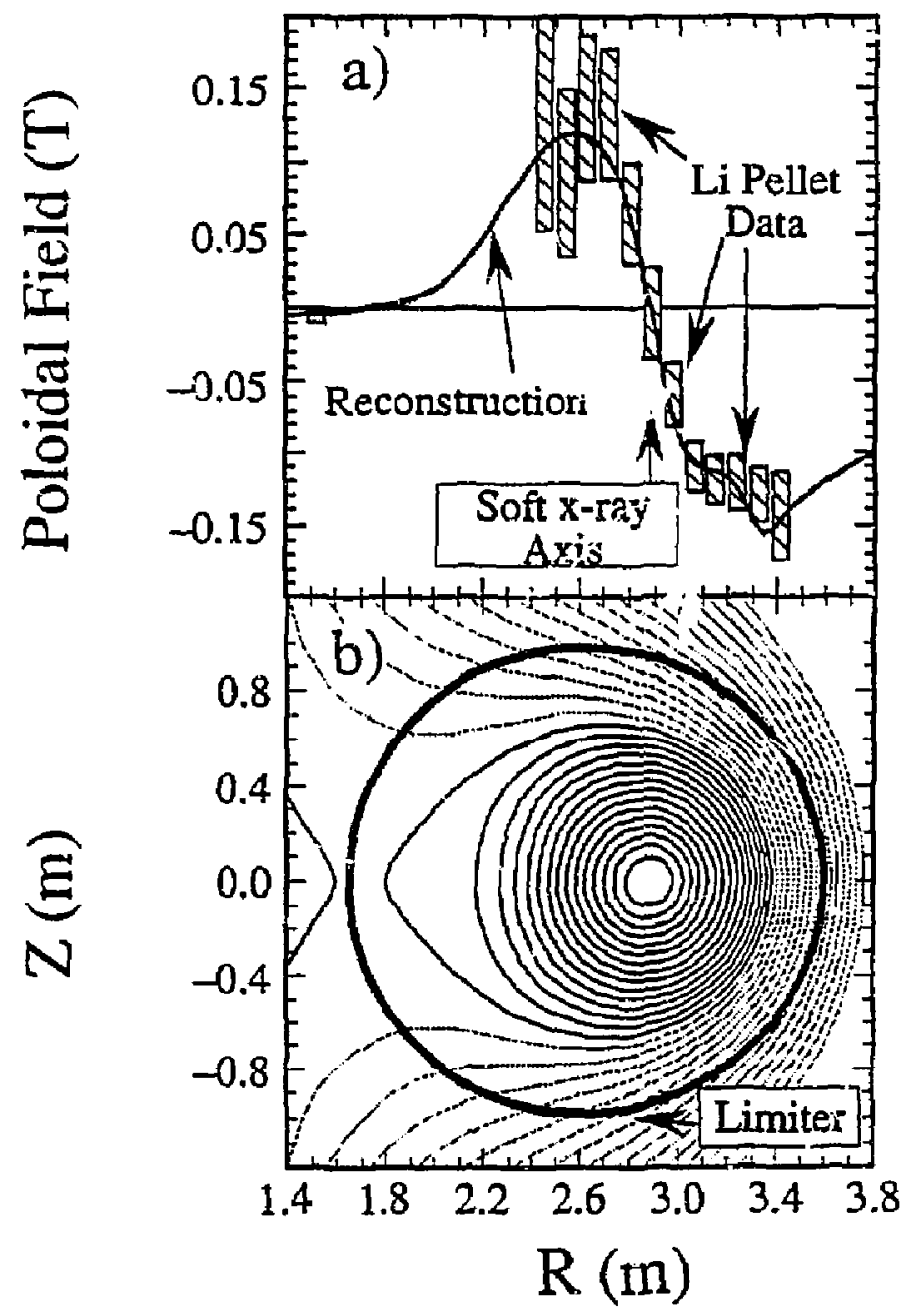




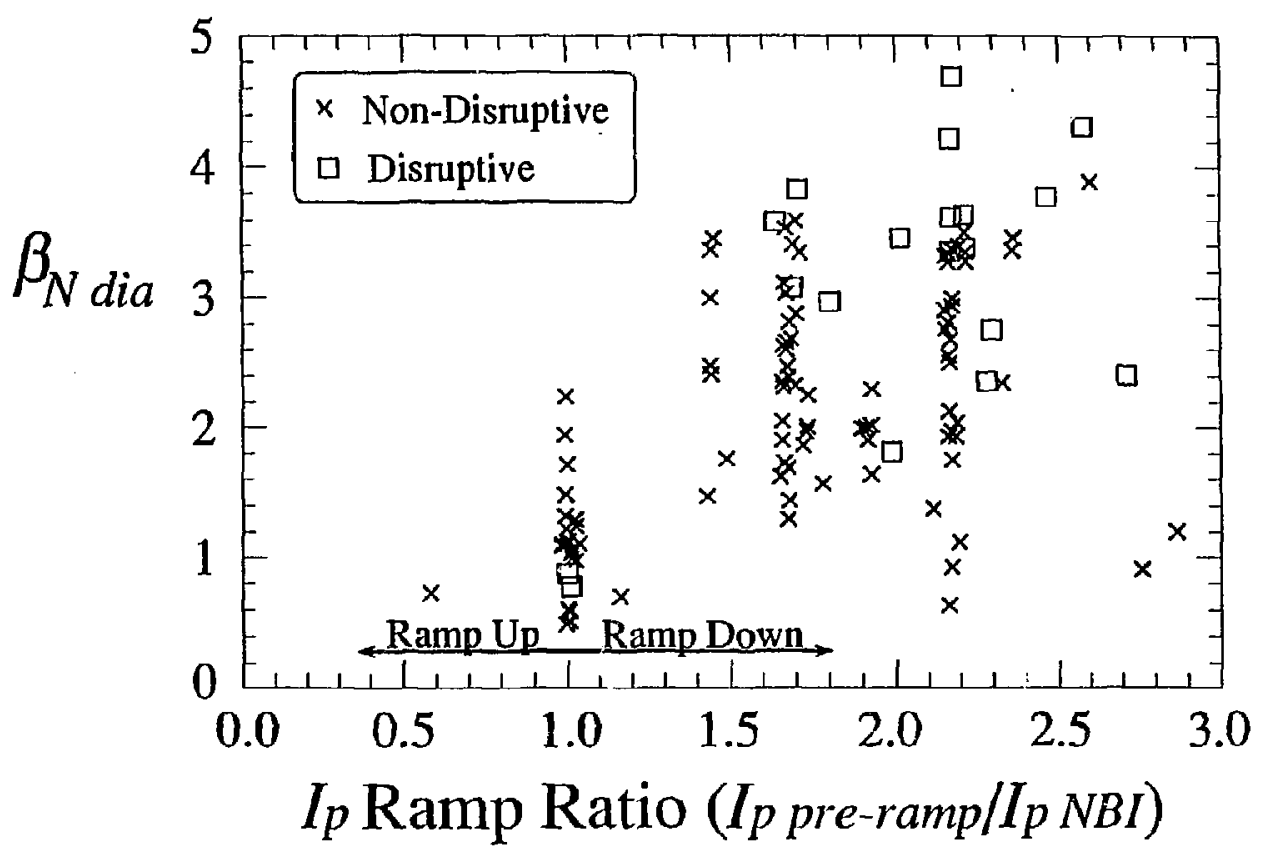




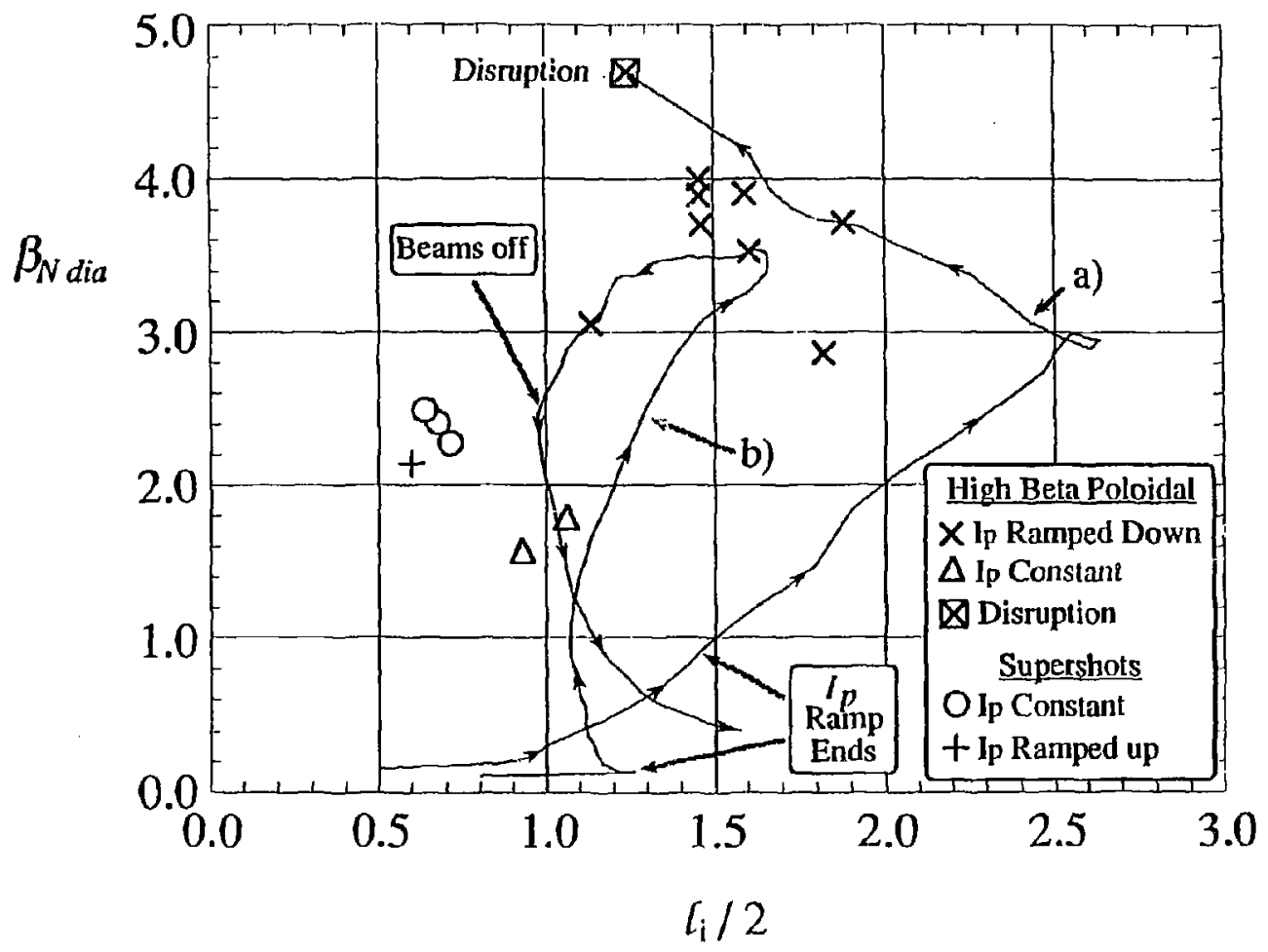


Fig. 7

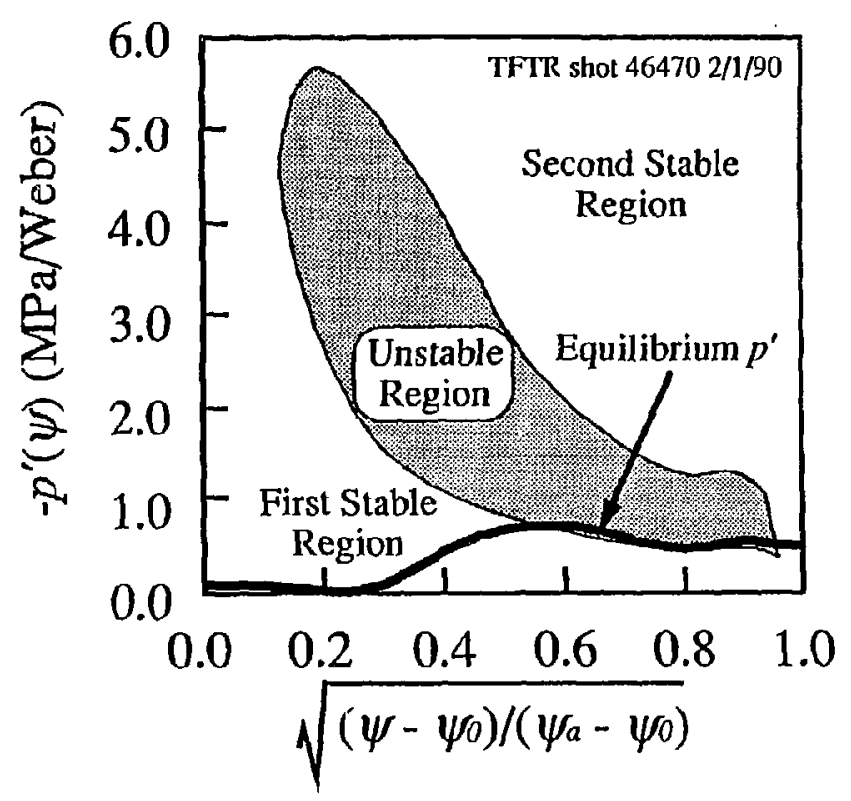


Fig. 8

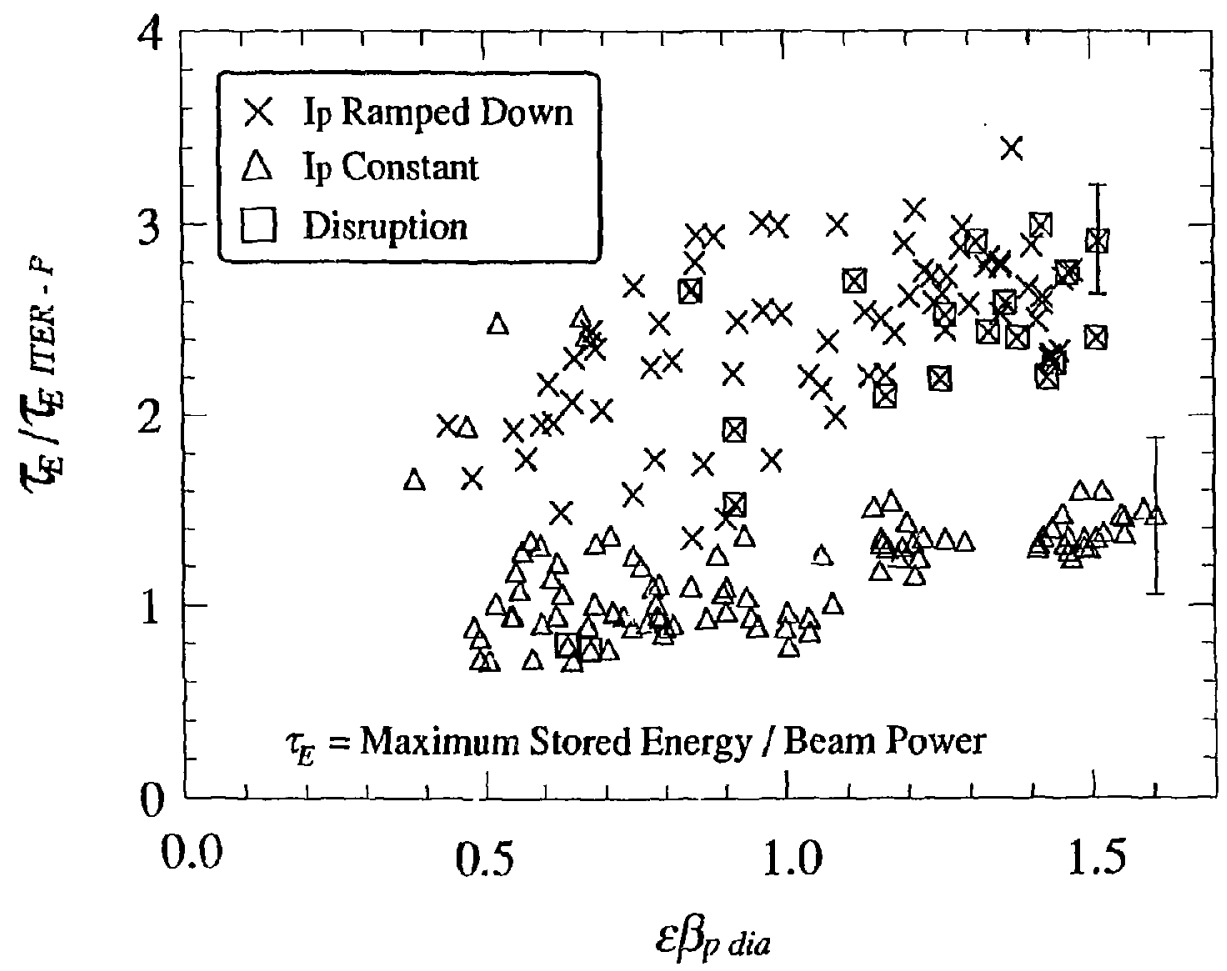


Fig. 9

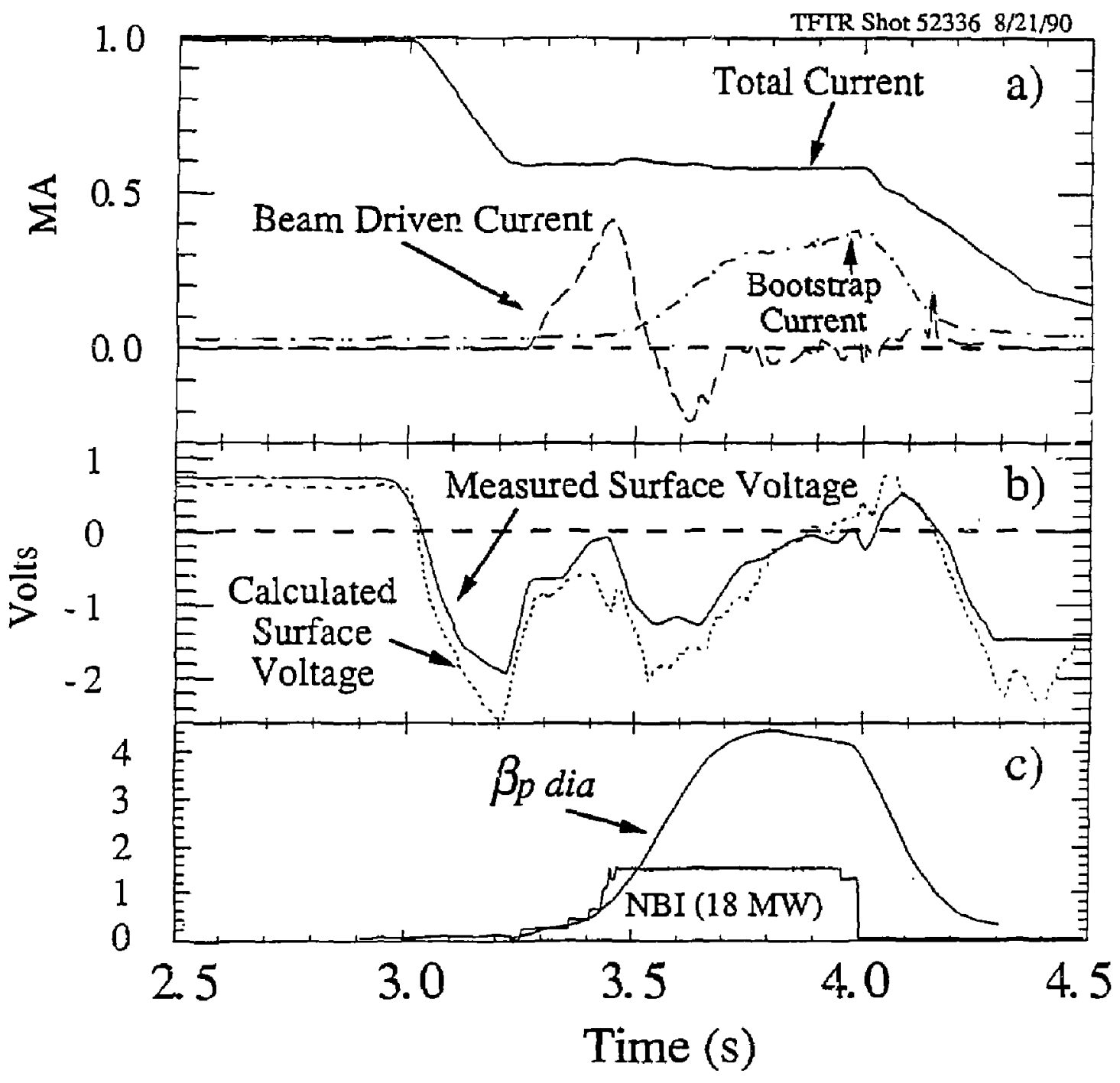


Fig. 10

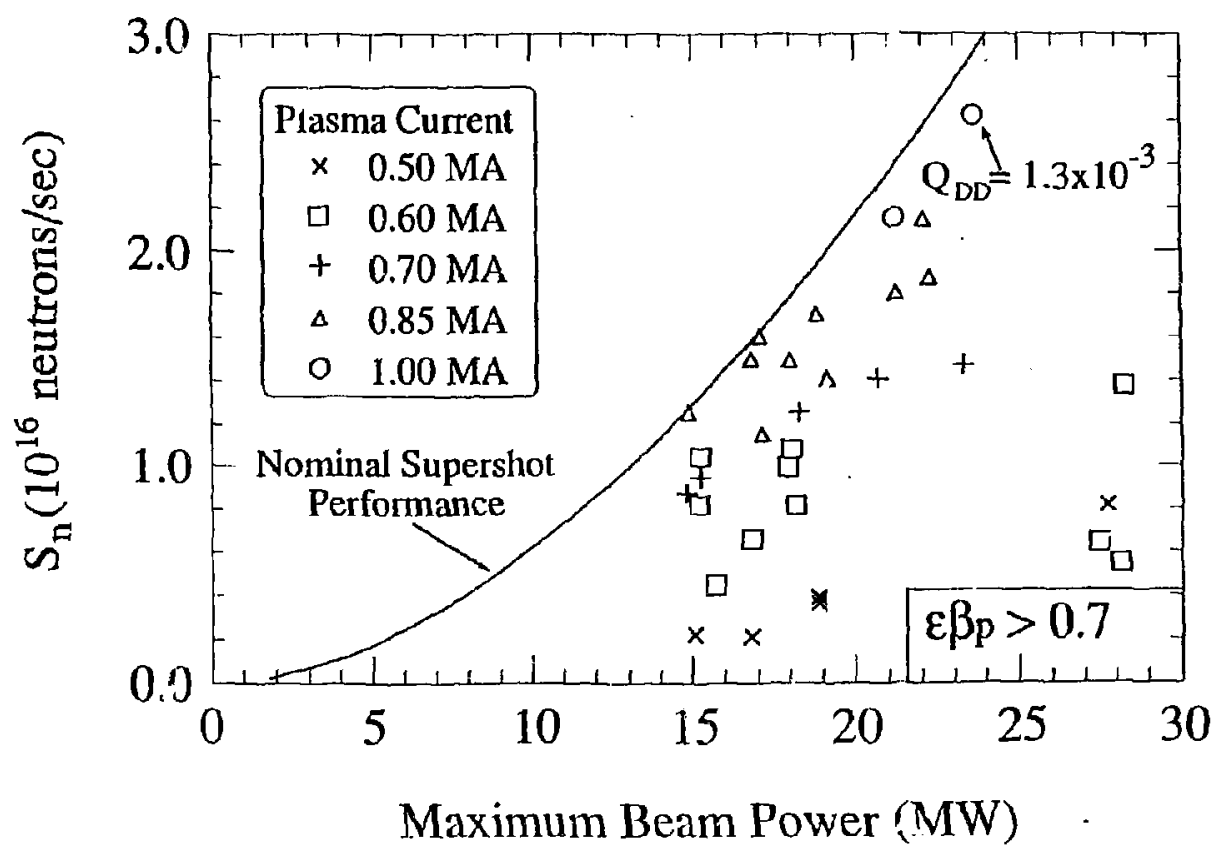

